\title{
Adversariality and Argumentation
}

\author{
JoHN CASEY
}

Philosophy Program

Northeastern Illinois University

5500 N. St. Louis Ave, Chicago, IL 60625

USA

j-casey1@neiu.edu

\begin{abstract}
The concept of adversariality, like that of argument, admits of significant variation. As a consequence, I argue, the question of adversarial argument has not been well understood. After defining adversariality, I argue that if we take argument to be about beliefs, rather than commitments, then two considerations show that adversariality is an essential part of it. First, beliefs are not under our direct voluntary control. Second, beliefs are costly both for the psychological states they provoke and for the fact that they are causally related to our actions. As a result, argument involving agreement can also be understood to be adversarial.
\end{abstract}

Résumé: Le concept d'opposition, comme celui d'argument, admet des variations importantes. Par conséquent, j'estime que la question de l'argument opposé n'a pas été bien comprise. Après avoir défini « argument opposé », je soutiens que si nous supposons que l'argument concerne les croyances plutôt que les engagements, deux considérations montrent que l'opposition en est un élément essentiel. Premièrement, les croyances ne sont pas sous notre contrôle volontaire. Deuxièmement, les croyances sont coûteuses à la fois pour les états psychologiques qu'elles provoquent et pour le fait qu'elles sont liées de manière causale à nos actions. Par conséquent, un argument qui mène à un accord peut également être compris comme étant oppositionnel.

Keywords: Adversariality, ancillary adversariality, argument-as-war, beliefs, commitments, disagreement, doxastic voluntarism, Govier, minimal adversariality.

\section{Introduction}

Argument is commonly understood to be an adversarial contest, with arguers as warriors or competitors who attack and defend positions in the hopes of scoring points, vanquishing opponents. In one particularly egregious example, a ubiquitous advertisement on 
Youtube invites viewers to watch "Ben Shapiro destroy liberals with facts and logic." Given the prevalence of such descriptions, it is thus no surprise that, among students in introductory courses in critical thinking, argument has a reputation of being a hyperaggressive, competitive, and unpleasant activity (Gilbert 1997; Goodwin 2005). Tragically, the arguer as warrior is also a common, and not entirely unwarranted, stereotype of philosophers. One author at Scientific American recently compared philosophy to "a martial art," remarking that he is "often struck, watching philosophers interact, by their aggression" (Horgan 2017). He punctuated this comparison with the depressing observation that like martial arts, philosophical combat produces no results. One thing that is noteworthy is that the prevalence of the adversarial conception of argument in everyday discourse stands in marked contrast to its place in argumentation theory; few scholars of argumentation defend it, and, what is more, introductory texts on argumentation typically take great pains to distinguish agonistic quarrels from arguments, usually in the very first pages. ${ }^{2}$ While what argument theorists reject about adversarial argument varies according to the theorist, we can distinguish three main strains of objection.

One strain is that argument is aggressive, mean, and generally unpleasant on account of our tendency to describe it that way (Lakoff \& Johnson 1980). Thus, arguers defend positions, attack claims with devastating objections, and other similarly belligerent

\footnotetext{
${ }^{1}$ https://knowyourmeme.com/memes/ben-shapiro-destroys-liberals

2 There are countless examples. Here are two well-known texts. Hurley (2008), a very popular general logic text, makes this point on page 1: "the term argument has a very specific meaning in logic. It does not mean, for example, a mere verbal fight, as one might have with one's parent, spouse, or friend" (p. 1). Govier (2010) writes: "In this book, however, the word argument is not used to refer to a fight or dispute. Rather, an argument is a reasoned attempt to justify a claim on the basis of other claims. Both kinds of argument - rational arguments and fights-have some connection with disagreements between people. When we use arguments in the sense of offering reasons for our beliefs, we are responding to controversies by attempting rational persuasion. If we engage in an argument in the sense of a fight, we shift to other tactics, often including the resort to physical force. It's important to keep the two senses of the word argument distinguished from each other" (p. 2)
}

(C) John Casey. Informal Logic, Vol. 40, No. 1 (2020), pp. 77-108 
metaphors. This conceptual machinery then occasions bellicose, or, more generally, adversarial behavior among arguers. This includes competitive manoeuvring such as adopting standpoints for strategic, not epistemic reasons, or a preference for nitpicky criticisms that facilitate point-scoring, or the intentional committing of fallacies. Ironically, there is a sports analogy that illustrates this point. Sport is a rule-governed activity founded on the concept of competition in the spirit of fair play. To describe sport in bellicose terms is, on this analogy, to encourage the erosion of norms of fairness and competition such as strategic rule-breaking or dirty play (Aikin 2011). Central to this thesis is the idea that the metaphors are optional (Lakoff \& Johnson 1980: p. 9). Given this, the solution to this problem of adversariality readily suggests itself: use other metaphors. Why not cross pollination or barn-raising (Cohen 1995)? We might even view arguers as lovers (Brockreide 1972).

A second approach to the problem admits that adversariality is an inherent feature of some, but not all, kinds of argument. Walton and Krabbe, for instance, argue that argument is dialogue and dialogues are understood according to their different purposes. Among these purposes are inquiry, persuasion, negotiation, deliberation, information seeking, and, importantly, eristic or quarrelling (Walton \& Krabbe 1995 p. 66). Crucially, only some of the forms of argument dialogue - persuasion dialogue and eristic - are essentially adversarial (and only eristic or quarrelling truly exemplify the negative sense of adversariality). Adversarialism becomes a problem when, for some reason-perhaps sexism, convenience, legalism, or cultural chauvinism-adversarial kinds of argument are overrepresented and so crowd out more collaborative forms of argumentation. The result is that people mistakenly think of argument in general as a fundamentally and entirely adversarial undertaking. This is what Janice Moulton means by the "adversary paradigm," where the argument-as-refutation style of the stereotypical philosophy seminar is the dominant method (Moulton 1983).

A third way to conceive of adversariality in argument is not as a description or a choice, as with the first two, but as an essential feature of the interaction. Govier (1999) maintains that a certain 
element of adversarialism is essential to and therefore ineliminable from argument. She discovers this in an analysis of the fundamental components of arguments, i.e. in beliefs or commitments rather than the procedural features of sharing reasons. Having a commitment to $p$, for Govier, puts one in a kind of adversarial opposition, even if only logical or dialectical, to those who do not hold that $p$. This essential adversariality, however, need not be any more than the bare logical entailment that if $p$ then not- $p$ is false. Anything more, she argues, is "ancillary adversariality," by which she means all of the aggressive nastiness of disagreement. While those who hold $p$ and those who hold not- $p$ may be in dialectical opposition, it does not follow that they need to be in emotional, rhetorical, or psychological opposition.

Govier's view has been challenged by Rooney (2010) and Hundleby (2013). They separately argue that Govier's account of minimal adversariality is (1) epistemically mistaken and (2) prone to a kind of dialectical slippage into ancillary adversariality. It is epistemically mistaken because arguments do not have winners, losers, or opponents. It is prone to a kind of slippage towards adversariality because viewing argument like a contest will likely make it so, as Lakoff and Johnson argue. There already exists a terminology suitable to the task of describing adversarial views without the adversarial language. Importantly, while Rooney and Hundleby clearly disagree with Govier about the nature of adversariality and argument, they follow her in the view that it is a fundamental question about the nature of argument rather than a question of descriptions of argument interactions or choices of argument forms.

In this paper, I will argue for a variation of Govier's view and maintain that argument is adversarial, not only in some unfortunate misdescriptions, or in some of its particular and possibly unhappy manifestations, but in itself. That is just what it is. Argument is adversarial to the extent that one arguer attempts to exercise control over the beliefs of another arguer. The criticisms of Govier's position, I shall argue, are enlightening in that they reveal a basic ambiguity about arguments that is endemic to argumentation literature, that is, are arguments relations of propositional commitments, or alternatively, are they relations of beliefs? The 
difference is a critical one because, plausibly, you have direct, voluntary control over your commitments but not your beliefs. More significantly, beliefs have significant costs associated with their formation, preservation, revision, and extinction. Furthermore, beliefs can be significant parts of one's identity, and so altering them, even through rational argument, constitutes a significant intrusion on the autonomy of another person.

The paper unfolds as follows. Since claiming that argument is adversarial naturally involves claims about both argumentation and adversariality, I begin in $\$ 2$ by rehearsing some classic and hopefully uncontroversial distinctions between argument as a process and argument as a product. I then turn to what is likely going to be a more controversial discussion of the relation of the concept of argument to disagreement, because, after all, disagreement seems to many people to have something to do with adversariality. I argue here that it is important to distinguish the two concepts because argument is just as much about agreement as it is about disagreement. I turn then to a discussion of the nature of adversariality where I distinguish between adversariality of interest (where participants engage over something that cannot be shared, such as material goods) and adversariality of process (where the relation between participants is determined by involuntariness). Critically, adversarial processes can apply to circumstances where there is no material or otherwise unshareable object. Having defined argument and adversariality, in §3 I review Govier's concept of minimal adversariality along with Hundleby's and Rooney's criticisms of it. In $\S 4$ I argue for a modified version of Govier's thesis where arguments are essentially adversarial because beliefs are involuntary. That argument is adversarial seems more urgently to be the case when we consider that aside from their involuntariness, beliefs are costly to us in their formation, maintenance, and extinction. $\$ 5$ concludes with a brief discussion of the implications of my view of adversariality for the problem of adversariality in argument. 


\section{Argument, disagreement, and adversariality}

It is standard in argumentation theory to distinguish between argument as a product (or argument 1 ) and argument as process (or argument 2 )(O'Keefe 1977; Brockriede 1977). As a product, an argument is an utterance, a communicative act, a set of sentences or propositions, a premise-conclusion complex, or an illative core (Johnson 2000, p. 150). This sense of argument has little obvious relevance to the concerns of adversariality, which, minimally, will involve more than one arguer. ${ }^{3}$ We see this in the conception of argument as process. As a process, an argument is an "interaction or transaction" (Brockriede 1977, p. 129). It is "something two or more persons have (or engage in)" (O'Keefe 1977, p.121). An argument, in this sense, is the exchange of argument products between two (or more) people or even between a person and themselves (O'Keefe 1977, p. 121). Put another way, an argument as a product is an argument (a noun), and as a process it is arguing (a verb). The process sense of argument is secondary, in a way, to the product sense.

A common view among process-oriented approaches is that argumentation is fundamentally about disagreement. According to Sally Jackson and Scott Jacobs (1980), "arguments are disagreement relevant speech events" (p. 254). Rhetorical theorist Michael Gilbert (1996) has an even more expansive sense of the place of disagreement in argumentation: "an argument is any disagreement - from the most polite discussion to the loudest brawl" (p. 5). Along these same lines, Charles Willard (1989) writes "argument is a form of interaction in which two or more people maintain what they construe to be incompatible positions" (p. 1). The idea that argument begins in disagreement is also robustly present in pragma-dialectics. This is evident not only in its definition of argument as "a verbal, social, and rational activity aimed at convincing a reasonable critic of the acceptability of a standpoint" (van Eemeren \& Grootendorst 2004, p. 1), but also in its description of the process of argumentation. This process begins in a

\footnotetext{
${ }^{3}$ It is true, however, that introductory textbooks on logic will cite the product sense of argument as evidence that argument itself is fundamentally not adversarial. See note 2 above.
}

(C) John Casey. Informal Logic, Vol. 40, No. 1 (2020), pp. 77-108 
confrontation stage where the difference of opinion is made explicit (p. 60). In the ensuing argumentation, a "protagonist" and an "antagonist" seek a resolution to an initial disagreement in their favor in a competitive, but rule-bound exchange (61-62). ${ }^{4}$

Historically, informal logicians have tended to focus on product-oriented conceptions of argument. Nevertheless, they do not neglect to identify arguments in their broader dialectical context, which is, unsurprisingly, disagreement or controversy. Trudy Govier writes,

An argument is a reasoned attempt to justify a claim on the basis of other claims.... When we use arguments in the sense of offering reasons for our beliefs, we are responding to controversies by attempting rational persuasion. (2010, p.2)

As we shall see in more detail presently, Govier derives the inherent adversariality of argument from the controversies they are meant to address rather than the method of addressing them.

It is certainly not true that every argumentation theorist founds argument in disagreement. Walton (1998) and Moulton (1983), as we have discussed, view disagreement resolution as one among many argument functions. Goodwin (2007), in contrast, denies that argument has any specific function. Exceptions aside, disagreement certainly looms large in argumentation theory, and it seems natural to assume that people who disagree are adversaries precisely on account of the disagreement. But this assumption masks considerable complexity to the relation between disagreement and adversariality and between adversariality and aggressiveness. As we have seen already, for some theorists, adversariality does not regard the content of an interaction but rather the manner of interacting. So, what is worrisome about adversariality is the aggressiveness of argumentative encounters. Thus Moulton, and others, worry that arguers will treat each other like adversaries when there are other, non-adversarial means of interacting. Others maintain that adversariality abides, in our (mistaken) conception of arguments, as zero-sum affairs with prizes for winning. Their worry is that we act these conceptions out when they are not appropriate.

\footnotetext{
${ }^{4}$ See Krabbe (2009) for a discussion of competition and argumentation from a pragma-dialectical perspective.

(C) John Casey. Informal Logic, Vol. 40, No. 1 (2020), pp. 77-108
} 
Still others, like Govier (1999), define adversariality in reference to the content of a disagreement, where people are adversaries because they believe different things or espouse different commitments. It is clear, then, that what argument theorists mean by "adversary" or "adversarial" varies significantly. A more problematic assumption is that disagreement is a necessary condition of adversariality when it might turn out that agreement is also in some sense adversarial. An adversary might after all be a friend who works contrary to your interests. ${ }^{5}$ They agree with you and you with them, but the agreement is bad. Even worse, this "friend" might, on account of the friendship, use collaborative or (allegedly) non-adversarial kinds of consensus-building arguments to further their adversarial ends. This kind of case, at minimum, suggests that it is time to revisit what it means to be adversarial in a fundamental sense. This is what I turn to now.

Where to begin? A common approach to the topic of adversariality in argument is Govier's. She writes:

It means that in this practice people occupy roles that set them against one another, as adversaries or opponents. Law, in Western societies is adversarial in the sense that the prosecution and the defense play distinct and opposed roles. Politics is adversarial: it is the role of the governing party to govern and the opposition to criticize the government. Debates are also organized adversarially: one side proposing a claim, the other side opposing it. In these institutions, roles have been organized in a bipolar fashion and the people occupying them are, for institutional reasons, set against each other (p. 242).

But this approach is problematic. First, law, politics, and debate are fundamentally argumentative practices, so they cannot explain the adversariality of argument. If anything, they get their adversariality from the fact that they are argumentative practices.

Second, they are rule-bound (at least in the case of law and debate) forms of argumentation, so they can, at best, only tell us about some arguments or some forms of arguments. Sadly, many arguments in common life do not seem to obey the rules, though

\footnotetext{
${ }^{5}$ It is perhaps not for nothing the Devil is called "the adversary" in Christian literature.

(C) John Casey. Informal Logic, Vol. 40, No. 1 (2020), pp. 77-108
} 
they are nonetheless arguments. Finally, as rule-bound practices, politics, debate, and law are artificial, while the claim on the table is that argument is essentially adversarial. By "essentially," in this case, Govier clearly means something like "naturally" or "ineliminably," "inherently," "in virtue of its nature," or some other such phrase. This is not, of course, to say that politics, debate, or law do not offer us insights into the nature of argument's adversariality. It is merely to hold that they do not define it.

What, then, is adversariality? For what it is worth, the etymology of the term, the Latin adversarius, refers broadly to any kind of antagonist in a contest, election, game, discussion and so on. This is not much help, but it at least suggests that adversariality minimally requires, as a definitional matter, participants who are the adversaries. This means that adversariality is a relational state, and relational states require relata, in this case (mostly) people standing in a relation of some kind. This is borne out by common examples. Any kind of physical fight is adversarial, and that certainly requires two people or animals; lawsuits require defendants, hockey requires two teams, and chess requires two players though nowadays one of those players can be artificial (perhaps in some dystopian future the same will be true of hockey as well). A rock climber, or a mathematician, may even speak (metaphorically) of an inanimate object or a concept as an adversary. Sometimes people speak of themselves as their own adversaries. Nevertheless, to say that an adversarial situation requires two adversaries is not to say very much. The tango, after all, requires two participants, but it is not adversarial. What is it then that makes an interaction adversarial?

That we are talking about a relational interaction gives rise to a fundamental ambiguity about the nature of adversariality. For, on the one hand, we might consider adversariality with respect to the object of some interaction such that one wins and the other loses. Let's call this adversariality of interest. In another sense, we might consider adversariality as definitive of the nature of the interaction between two people such that they are adversaries if they behave a certain way in an interaction. Let's call this adversarial interaction. Let's first look at adversariality of interest. 
Adversariality of interest regards something two people, in a simple case, both want but cannot both entirely possess. To use the language of economics, they contend over a "rivalrous good" which is "excludable." A rivalrous good is one that is to some extent scarce such that one person's having it means another necessarily has less (or none) of it. These adversarial goods are excludable because the possession of it by one precludes the other from having it. On this description, that adversariality only regards alienable objects or rather interests with respect to alienable objects. We can put this a bit more formally and define adversariality of interest by reference to opposed or inconsistent interests. I want $p$ and you want $p$ but we both can't have $p$. Our interests with respect to $p$ are therefore opposed in the sense that they are inconsistently satisfiable. So, $A$ and $B$ are adversarial with respect to $p$ only if $p$ is something both $A$ and $B$ want to have, try to have, but both cannot have. This picture is naturally simplified. Perhaps it is the case that $A$ and $B$ can have some, but not all of $p$. $A$ 's interest (which is a vague notion on purpose; it could include desire, etc.) is to have all of $p$. Or, at the very least, $A$ wants what $A$ wants. The adversarial situation arises because of $B$, because $B$ exists, wants $p$, and tries to get it. They can split it, but this is less than what $A$ wanted. There is no adversariality of interest without the inconsistency feature. The main characteristics of adversariality of interest situations is the end-state division of the spoils. You might even say, since the objective is definitive, this is the only characteristic. So, winning and losing are appropriately applied to these cases. By way of example, two motorists can be adversaries with regard to the one remaining parking spot-it will go to whoever gets there first (or however it is decided). But we can characterize other adversarial situations by reference to rivalrous goods. People who play a game are adversarial with respect to the acquisition of points or the achieving of a goal because victory in a game is often determined by the scarcity of some kind of goal or end state; only the winner can have it. In addition to parking spots and sports, this sense of adversariality captures some aspects of the adversarial nature of many other things: law, where parties contend over some material good or state action (guilt or innocence); business, where 
parties compete for market share; or finally, war, where only one side can win (though many say both actually lose).

It often seems that many concerns over adversariality in argument regard the adversariality of interests. Thus, Cohen (1995), among others (Johnson 2000 and Rooney 2010) wonders what sense it makes to "win" an argument when only the loser, if anyone, actually makes any sort of gain (by having their views improved). As Johnson notes, the language of winner, loser, or opponent, and so on, is wholly foreign to the primary epistemic aim of argumentation, truth or justified belief, which arguers presumably share as a common objective. Bailin and Battersby (2017) put the matter poignantly:

Argumentation involves the confrontation of ideas with the goal of reaching the best justified position but this need not and indeed should not be viewed in terms of a conflict between individuals. Arguers may come to an argument with various initial intentions including, but not limited to, wanting to persuade their interlocutor of a different view. But so long as they are open to seriously considering alternative arguments, and willing to follow the reasoning where it leads and to alter their own position accordingly, they are involved in a joint endeavour and are not opponents (p. 4).

Since true beliefs are non-rivalrous and non-excludable, that one person has a true belief does not deny others the possibility of also having that true belief. If this were the only kind of adversariality to worry about, it would hardly pose a very vexing problem. It is of course true that people often weaponize argument performances for other purposes, such as increasing social status, political advantage, or bragging rights. But these do not speak to the inherent adversariality of argument any more than a baking competition represents the inherent adversariality of eating cookies. The concern over adversariality, of course, remains because there is another way to understand adversarial interactions.

To see what is distinctive about adversarial interactions, as interactions, let us contrast them with cooperative or coordinated interactions. The tango, or any kind of dance, is a kind of cooperative interaction involving two dancers. The same could be said of musical duets, gardening, construction, and other similar endeav- 
ours where two people might participate. In these activities, the participants agree to play complementary roles (such as lead and follow in the case of dance, or violin or banjo in the case of a duet). As a consequence of their complementary roles, each participant contributes to the construction of a common objective or product (a dance, a piece of music, and so forth). In contrast, if two people, $A$ and $B$, interact as adversaries, then the action of $A$ on $B$ and $B$ on $A$, for the purpose and duration of the adversarial exchange, is characterized by involuntariness; $A$ will try either to impose a result on $B$ or frustrate $B$ 's attempt to do the same to $A$. This means that an adversary is both one who frustrates your action and one who compels you do to something. ${ }^{6}$

What might be a base case of this kind of adversarial interaction? Brute physical interaction, where $A$ forcefully compels or frustrates $B$, would seem to qualify. $A$ 's force overcomes $B$ 's will, so the interaction is involuntary. For this reason, it seems sensible to say that involuntariness is a basic condition of an adversarial interaction. It is certainly the case that adversarial interaction can obtain in the absence of some kind of contestable object. Fights are certainly adversarial even if there is no point in their taking place. The same is true of other applications of physical force, such as shoving someone, or restraining someone (say, in handcuffs). These possibilities clearly distinguish, then, cases of adversarial interaction from cases of adversariality of interest. There is not some rivalrous good to be contested, but rather one's own control over one's own body and action. In this sense, criminal law is adversarial because it operates on force alone without respect to a good.

Other cases of adversarial interaction are less pure, as it were, because the involuntariness regards a contestable good. In the parking example mentioned earlier, the occupation of a certain parking spot with your car frustrates someone's desire to park there and, presuming they don't have a tank, compels them to park elsewhere. Nonetheless, the interaction, involving your car, or

\footnotetext{
${ }^{6}$ It is an interesting question as to whether these are two sides of the same coin. Without wandering too far from our main focus, it does seem that what counts as frustration and what counts as compulsion are very closely correlated.

(C) John Casey. Informal Logic, Vol. 40, No. 1 (2020), pp. 77-108
} 
perhaps the law or other rules in case there is some other prohibition, is independently adversarial. We can also see this in games. In chess, this occurs by movement of pieces and the occupation of spaces on the board; in hockey, this is achieved sometimes by moving the puck, sometimes by actual physical contact, such as checking.

The adversariality of games and certain other interactions, as we have noted above, raise interesting questions. In the first place, they are artificial. The object of an adversarial game depends on what people desire it to be. In the game of chess, the object is to seize the opponent's king or force them to concede. In hockey and other similarly structured sports, the object is to have more points than the other team. Second, in addition to defining the object of the adversarial interaction, games also define the nature of the interaction - what sorts of contact is allowable, what is not. In this sense, the adversariality of games is derivative and regulated. Chess, for example, regulates what counts as a legal move. Hockey does the same, and it penalizes (with time in the penalty box) prohibited interactions (though to a novice spectator it seems like anything goes). To return to a point we made earlier, these observations apply just as well to debate competitions and the law; they define an objective and set regulations for the kinds of things that can be said. Fundamentally, however, within the scope of the game, the adversarial interaction is characterized by involuntariness because the participants are each trying to control the other's play.

At this point one might object that to call parking and other similar activities adversarial too greatly expands what counts as adversarial. And this definition seems to run the risk of diluting the concept and rendering it useless. Indeed, there is only so much space for you (or your car) and your occupying that space means someone else cannot. It is hardly helpful to consider the worlds highways and pavements ground zero of an infinity of adversarial relations. In reply, however, there is no reason that that they cannot become adversarial in a basic structural sense. Besides, the fact that these interactions can become adversarial underscores the distinction between adversariality of interest and adversariality of interaction: interactions can become adversarial, marked by frus- 
tration and compulsion, in the absence of any kind of structured interest.

The happenstance nature of these kinds of adversarial circumstances suggests a further distinction. It seems that some adversarial interactions are essentially so. Chess, hockey, and many (but not all) kinds of sport require, as a necessary condition of playing them, compelling or frustrating the other player. ${ }^{7}$ But some kinds of activities that we consider to be adversarial become so only because the participants resolve to treat each other as adversaries. This is what makes running, cycling, or other kinds of individual sports adversarial. Beyond sport, we can apply the same analysis to essay-writing contests, music competitions, competitive chicken breeding, or, for some people, driving or walking on the sidewalk. This distinction also illustrates the independence of adversariality of interaction from adversariality of interest. Inessential adversarial interactions can, in other words, lack adversarial interaction.

So far, we've distinguished between two independent perspectives on adversariality: adversariality with regard to interests and adversariality with regard to interaction. The former perspective focuses on the rivalrous goods over which people contest; the latter concerns the manner of interaction, such that one participant tries to impose a result on another or frustrate them from achieving their objectives. Though the perspectives may overlap in certain scenarios, they are distinct and independent of each other. We made a further distinction between natural and artificial adversarial situations. Artificial adversarial situations are regulated and have objectives that are set by designation and interactions defined by rules, like chess, or debate. Some artificial adversarial interactions are essential, in that, for the duration of the interaction (e.g., within the scope of a game) the interactions can be nothing but adversarial. Others are not essential, because the adversaries do not necessarily interact with each other in order to play the interaction. The purpose of this rather long discussion of adversariality is to determine whether and in what sense argument is adversarial.

\footnotetext{
${ }^{7}$ A helpful distinction borrowed from philosophy of sport is that some contests are encumbered, where the actions of the participants affect each other (e.g., hockey); some are unencumbered, where their actions do not affect the other (figure skating). See Skultety (2011 p. 441).
}

(C) John Casey. Informal Logic, Vol. 40, No. 1 (2020), pp. 77-108 
The question for the next sections will be, then, whether argument is an essentially and naturally adversarial interaction.

Given this rough picture of adversariality, a natural question is whether adversariality and aggressiveness are the same thing. Much of the controversy about adversarial argument hinges on this question. One view is that they are indeed the same as to be adversarial involves the desire to impede or compel someone else. To be adversarial simply means to be aggressive. Consider Dominic Infante's description of aggressiveness:

An interpersonal behavior may be considered aggressive if it applies force physically or symbolically in order, minimally, to dominate and perhaps damage or, maximally, to defeat and perhaps destroy the locus of attack. The locus of attack in interpersonal communication can be a person's body, material possessions, selfconcept, position on topics of communication, or behavior (1987 p. 158).

Interestingly, on Infante's view, argument is a form of aggressive communication. It is natural, I think, to conclude that adversariality and aggressiveness strongly overlap. But this is not the only or even the most obvious view. An alternative view is that aggressiveness and adversariality merely overlap but are not the same. Aggressiveness, on this view, might consist in intention to do someone harm, where harm extends to the person beyond the person's role in a contest (Bäck, 2004, p. 221).

Clearly, aggression and adversariality overlap and sorting out their differences is not easy. Ordinary usage is not much of a guide as the terms are often used interchangeably (this is also true of the literature in argumentation). Perhaps we might start by conceding that aggressiveness and adversariality overlap to the extent that aggressive acts will include the attempt to frustrate or compel. To put it bluntly, all aggressive encounters are adversarial encounters. Is it the case, however, that all adversarial encounters are aggressive? This is the critical question. I think there a few good reasons to think they are not the same.

The first reason is, at least as I have defined it, adversariality can be understood structurally. Certain kinds of encounters, I have argued, are necessarily adversarial whether or not the participants want them to be so. Hockey and chess are adversarial so long as (C) John Casey. Informal Logic, Vol. 40, No. 1 (2020), pp. 77-108 
the rules are followed. This remains the case no matter how badly one side loses or fails to put in a serious effort. To put this another way, they are not more or less adversarial. They are adversarial or not. We can extend this to what I have called the "inessential" cases. Driving along the road is not adversarial until space becomes limited and people try to outdo each other. There is not a period of low or medium adversariality. It is the case or it is not. Adversariality is, in other words, a state and not a process. By contrast, aggressiveness seems to admit of degree. One can play a game of chess more or less aggressively (by, say, going on the attack rather than playing defence). One can be more or less aggressive in the inessential cases as well-elbowing one's way through a crowd or cutting off drivers on the road.

The second reason is that aggressiveness seems to be optional. It is obvious to everyone, I hope, that some of our adversarial encounters have worrisome features. It is typically the case that these are associated with aggressiveness. Driving in traffic is one thing, but doing so amidst angry honking, obscene gestures, and dangerous maneuvers is another thing. Those latter things make the experience unpleasant and dangerous. More significantly, they seem, however predictable, to be optional. Traffic exists without honking. A hockey game still occurs without fighting or slashing. We can do without them.

Finally, closely related to this reason is that aggression is the territory of useful normative notions about our adversarial interactions. Too much aggressiveness is indeed a bad thing. Rule systems in games are constructed to contain aggressiveness. A helpful example of this is American football. American football is, on any account, a violent sport. It nonetheless contains a robust (but still perhaps inadequate) set of rules meant to curb the worst of the violence. "Targeting," which is leading into a tackle with one's helmet to hurt another player, is prohibited as overly aggressive because it is dangerous. It is an extreme version of the allowable action called "tackling." Separating aggressiveness from adversariality, in this instance, allows the game to continue. Indeed, we might say that when aggressiveness undermines the purpose of the adversarial encounter, it ought to be prohibited. Defending that claim is of course well beyond the scope of this paper. It is none- 
theless clear from this, I hope, that adversariality and aggressiveness occupy different normative terrain.

I should add, in closing this section, that the existence of a distinction between aggressiveness and adversariality does not of course mean that it is an easy one to spot in all or even most cases. The substance of debates about what is allowable seems to rest, in fact, on this troublesome distinction.

\section{Minimal essential adversariality}

Armed with our discussion of adversariality, let's now turn to the question as to whether argumentation is essentially adversarial in the sense I have just described. To review, an adversarial interaction is one involving two participants each of whom tries to impede or compel the other. In what follows, I will apply this notion of essential adversariality to Govier's concept of minimal adversariality.

Govier's notion of minimal adversariality rests on a distinction between adversariality and aggression (or what Govier calls "ancillary adversariality"). This last she defines as the "lack of respect, rudeness, lack of empathy, name-calling, animosity, hostility, failure to listen and attend carefully, misinterpretation, inefficiency, dogmatism, intolerance, irritability, quarrelsomeness, and so forth" (p. 245). To say that argument is essentially adversarial is clearly to distinguish it from practices which are inessentially adversarial (such as the running race discussed above). This distinction accords with Govier's argument for minimal adversariality, which she puts schematically as follows:

1. I hold X.

2. I think that $\mathrm{X}$ is correct. (Follows from (1)).

3. I think that not-X is not correct. (Follows from (2)).

4. I think that those who hold not-X are wrong, or are making a mistake. (Follows from (3)).

5. Should I need to argue for X, I will thereby be arguing against not-X.

(?)

6. Those who hold not-X are, with regard to the correctness of $\mathrm{X}$ and my argument for X, my opponents (?) (p. 244).

For Govier, the adversariality of argument is reducible to the elements of argumentation (beliefs, opinions, or standpoints), 
rather than argumentation itself. This means that believing is inherently adversarial. If $A$ and $B$ believe differently, then $A$ and $B$ are already opposed because they hold different beliefs before or without even arguing with each other. She writes, "in holding a belief, one thinks it true and is thereby committed to thinking that those who disagree with it hold a false belief and are in this sense wrong. One necessarily differs from such people" (p. 244).

Phyllis Rooney (2010) raises two objections to Govier's claim: (1) Govier misdescribes the epistemic situation; and (2) the distinction between minimal and ancillary adversariality does not hold. The first objection is a general claim about the purpose of argument. From an epistemic point of view, arguments are about truth. The adversarial conception of argument is foreign to this. Besides, logic and epistemology have a much richer vocabulary to describe epistemic situations than just "opponent" or "adversary" (p. 222). To put the matter somewhat differently: the holding of different views doesn't mean the holders of those views are opposed. For Rooney, then, you cannot derive the opposition from the difference in belief. And, importantly, you cannot derive it from the nature of the argumentation, whose epistemic purpose is entirely contrary to competitive opposition.

The second objection rejects the inference from being wrong with respect to $p$ to being opposed, from a person's belief or claim to the person themselves (p. 221). This might seem puzzling because saying that a person has a belief which is false seems to be just another way of saying that a person is wrong with respect to that belief (which the person has). What is at issue in an argument is the truth or falsity of claims or commitments. If I argue that $p$ and someone else argues that $q$, we are not opposed with regard to the truth of $p$ (or $q$ ), which is, as Rooney argues, the very point of argumentation. To expand the point somewhat, our arguments are ways we propose arriving at the truth, a goal both arguers, by definition, share. So, since the point of arguing is truth, arguers are not opponents but partners. A similar analysis could be made of the language of "winner" and "loser." To describe the person with a correct view as the "winner" is to describe something as a contest which is not a contest. Terms such as "winner" and "loser" are a sign of an epistemic confusion about the nature of arguments. 
Arguments have epistemic purposes and are defined in relation to them.

This brings us to a crucial ambiguity in this discussion of adversariality: namely, what are arguments about? Are they about commitments (or acceptances) or are they about beliefs? The difference is foundational. Beliefs are psychological states of believers; acceptances are commitments that belong to an abstract commitment set. This is a crucial, but oft-overlooked difference in argumentation studies (Paglieri, 2006; Godden 2010, 2012b). Moreover, this distinction is central, I think, to Govier's case for the minimal essential adversariality of argument. This point comes clear, I think, in considering another objection to Govier's view, that of Catherine Hundleby (2013).

Recall that, for Govier:

1. I hold X.

2. I think that $\mathrm{X}$ is correct. (Follows from (1)) (1999, p.244).

Hundleby argues that there is no obvious inference from (1) to (2), because "we believe all sorts of things at any given time without consciously recognizing them as beliefs, never mind evaluating them" (emphasis mine, 253). This assessment seems obviously true and it makes a clarifying point about the basic point at issue here. As a psychological observation of actual believers, it doesn't make sense to attribute beliefs to them that they do not have or may not have (or at least do not necessarily have) even if those beliefs are logically related.

Hundleby makes a similar case with regard to the next steps of Govier's argument for minimal adversariality. Recall, again, that Govier argues:

2. I think that $\mathrm{X}$ is correct. (Follows from (1)).

3. I think that not-X is not correct. (Follows from (2)) (1999, p.244).

Again, it seems clearly true that all sorts of things are "not- $X$ " and one is certainly not liable for thinking of all of them. It is not possible to claim that in thinking $X$ you are also thinking of all of the instances of not- $X$. Imagine a typical introduction to logic scenario where students work with obversion and fail to recognize the logical identity. 
This objection also highlights a crucial confusion on Govier's part. Her talk about beliefs is better understood as talk about commitments. For, after all, commitments do have the logical properties in question. To be committed, for example, to the proposition that the earth is round is to be committed to the proposition that the earth has a circumference. It doesn't mean, however, that thinking of the roundness of the earth entails thinking about the circumference, or $p i$, or any of the other commitments one assumes along with the commitment that the earth is round.

Now the question is whether Govier's conception of minimal adversariality follows from the claim that arguments are about commitments, which do have the logical properties and entailments she suggests they have. This brings us back to Rooney's claim that minimal adversariality is an epistemic misdescription. Arguments will concern the assertion of relations between commitments, and, as Rooney notes, we've already got a vocabulary for those relations; "contradictory" or "inconsistent" express the difference in commitments far more accurately than "opposed" or "enemy" do (p. 222).

For these reasons, Govier's derivation of minimal adversariality from the notion of commitment fails. I should of course stress that Govier does not use the word commitment, or acceptance, or even suggest that this distinction concerns her in the least; my claim here is that this makes the most sense of her argument. For this reason, I would like to offer a somewhat modified version of minimal adversariality that addresses this issue.

\section{Doxastic involuntarism and minimal adversariality}

In this section I will defend Govier's minimal adversarialism by interpreting the minimal adversariality of argument to arise from beliefs, rather than commitments. This defence depends on two critical features of belief-focused argument. The first is that beliefs are involuntary. The second is that beliefs are expensive to form, maintain, and change. This means arguments, even those among people who agree, involve one arguer imposing costs on another.

The concept of commitment, as it is understood in argumentation studies nowadays, has its origin in Hamblin-style formal 
dialogues (Hamblin 1970) which was later refined by Douglas Walton and Erik Krabbe (1995). Hamblin introduced the idea "of a dialectical system - a rule-governed structure of organized conversation" (Walton and Krabbe 1995, p. 5). The idea is that these rule governed systems could be used to model various kinds of dialogical interaction. Such models could then perhaps be formalized, used to explain fallacies, and so forth. Critically, according to Hamblin, a commitment is not necessarily a belief and the purpose of postulating a commitment store is "not psychological" (p. 6). The very notion of commitment involves action, as in committed to a course of action (p. 14). But it also involves the concept of obligation, as in "obligation to pursue a course of action." According to Walton and Krabbe, propositional commitment is a special case of action commitment. Propositional commitment is "(1) a kind of action commitment whose (2) partial strategies assign dialogical actions that (3) center on one proposition (or a formulation thereof)" (p. 23). So, a propositional commitment works something like making a promise (e.g., if $\mathrm{X}$ asserts that $\mathrm{p}$, then $\mathrm{X}$ must defend $\mathrm{p}$, repeat $\mathrm{p}$, etc.). So, in essence, commitments are public actions which are subject to rules, and, most significantly, laws of logic.

In contrast, beliefs are typically understood to be psychological states or dispositions (Cohen 1992). They differ from commitments in several key ways. First, they are private. I can have beliefs which I do not share or beliefs I lie about. This is not true of commitments, which are understood to be public. Second, they are not necessarily subject to logical laws in their formation, maintenance, and extinction. To believe, in other words, that the Evening Star is Hesperus does not necessarily entail that one believes the Evening Star is also Venus. Those are distinct psychological states. A final critical difference between belief and commitment, as we have mentioned, is voluntariness. As actions, commitments are voluntarily adopted and abandoned. Beliefs, in contrast, are not. By way of illustration, try to believe that $5+4=11$. Now imagine I will offer you a reward of an ice cream cone if you can. Or, consider an inducement more relevant to the current topic: I'll refrain from hitting you if you believe that $5+4=11$. You probably cannot do it (although I am going to guess that you will tell me 
that you do not believe it). We can run the same experiment with different kinds of beliefs. Try to believe you are not reading the words that I have written here, or that you are not where you are, or that you are made of glass. You cannot.

I should caution that the literature on doxastic voluntarism is quite vast, and, though the consensus view is that beliefs are involuntary with regard to direct formation, there are obviously indirect things we can do to bring about beliefs. We can, for instance, (1) alter our environment to bring about beliefs-i.e. investigate, change things, make something happen, or (2) engage in a process of examining evidence. Naturally, we cannot control the specific belief we have (which would tend to produce the opposite result). We can only control what kind of evidence we have. Indeed, the fact that we have to manage our exposure to evidence underscores the involuntariness of significant aspects of belief formation, maintenance, and extinction. To maintain a belief, for example, I can avoid situations where I know I will have to face conflicting evidence. The same is true for strengthening a belief, I can seek out situations where I'll be presented with more evidence for my belief.

Our lack of direct control over our own beliefs has an important consequence for argumentation: others have more influence over our beliefs than we do. For many, this is one of the main virtues of this sense of argument: to submit yourself to the influence of others. While we cannot, according to the basic thesis of indirect doxastic voluntarism, direct ourselves to a specific belief, others, so it would seem, are in a position to do so. This kind of directing is what arguments are all about even at the most rational level. I expose you to evidence that gives you no voluntary option but to change your mind. Naturally, you have to grant me access to your belief system, but this is part of what is involved in agreeing to argue or agreeing to hear evidence. This fits in neatly with our picture of essentially adversarial practices in all three key ways but particularly with regard to the element of imposing. My sharing reasons with you is the way imposing is practiced in arguments. While this is certainly true of arguments involving explicit disagreements, it is just as true of arguments in the broadest sense possible, including those that do not involve any disagreement at 
all. The key feature of voluntariness, as I am discussing it here, is that others, even those with whom I agree, can alter my beliefs in a direct way by exposing me to argumentative evidence.

I should add a few cautionary notes about the distinction between beliefs and commitments, for some might object that typically our commitments track our beliefs. The things we are committed to in argument, in other words, are typically the things that we believe. The difference I mean to point out is rather that we are free to choose any particular commitment, develop arguments for it, and abandon it when we please. But this points to another important qualification. It is not entirely the case that commitments are voluntary. They are voluntary only in their initial adoption. I can choose, for example, to defend the thesis that the Egyptian pyramids were built by space aliens. Once I adopt that, however, I also acquire a series of other commitments - that there are aliens, that aliens visited the earth, and so on. To this extent, therefore, even commitments are involuntary. They are involuntary, however, by analogy to the rules of a game, and in fact this was one of the ways Hamblin spoke of them. This is part of the reason that commitment-centered argumentation theories speak about argument "moves." Consider, by way of illustration, Walton (1998):

The concept of a dialogue, in the sense developed in this book, is that of a conventionalized, purposive joint activity between two parties (in the simplest case), where the parties act as speech partners. It is meant by this that the two parties exchange verbal messages or so-called speech acts that take the form of moves in a game-like sequence of exchanges (p. 29; emphasis added).

This means the adversarialism of these encounters is of the derivative sort, where the adversarial position is adopted secondarily to the exchange. This differs in a key respect from beliefs, where the involuntarism is not optional.

The idea that argument involves involuntary imposition is not a particularly new one. Several authors, Gearhart (1979), Nozick (1981), Foss and Griffin (1995), and Fulkerson (1996) have advanced versions of this view. We might call this view "argument pacifism," where persuasion by argument is inherently something forceful, much along the lines of sports or war, and hence to be avoided. To be clear, their point is not that it is aggressively force(C) John Casey. Informal Logic, Vol. 40, No. 1 (2020), pp. 77-108 
ful - that arguers sometimes push too hard or are too rough, disrespectful or any of the other things that Govier termed ancillary adversariality, but rather that persuasion works in ideal circumstances against the will of the person being persuaded. Persuasion, in this sense, violates equity; you're not treating the other arguer fairly (Fulkerson, 1995). Sally Gearhart (1979) maintains that the problem lies in the desire to change someone else, which, for her, issues from a patriarchal desire to dominate:

Our rational discourse, presumably such an improvement over war and barbarism, turns out to be in itself a subtle form of Might Makes Right. Speech and rhetoric teachers have been training a competent breed of weapons specialists who are skilled in emotional manoeuvers, expert in intellectual logistics and, in their attack upon attitude and belief systems, blissfully ignorant of their violation of nature or her processes (p. 197).

Although Gearhart does not note the crucial role the involuntarism of believing plays in this, Nozick comes much closer:

Why are philosophers intent on forcing others to believe things? Is that a nice way to behave toward someone? I think we cannot improve people that way-the means frustrate the end. Just as dependence is not eliminated by treating a person dependently, and someone cannot be forced to be free, a person is not improved by being forced to believe something against his will, whether he wants to or not. The valuable person cannot be fashioned by committing philosophy upon him (p. 5).

The indirect voluntarism of beliefs is a two-way street. While it may be that a thoroughly persuasive argument leaves us in stunned silence or with no other option, as Nozick suggests (p. 6), we have little direct control over our belief system anyway. Argument, rational argument at least, may be the least invasive way to manage our belief system. Noting that persuasion is forceful, in other words, does not entail that non-forceful options even exist, or, if they do exist, that they are any better.

The central feature of any essentially and naturally adversarial practice is involuntariness. This bears on argument through the involuntarism of belief. Argument, so far as it is belief-focused, is essentially adversarial because to interact with someone's beliefs 
is to attempt to compel them. Alternatively, it may be to try to frustrate their acquisition of certain beliefs. As Nozick and Gearhart note, such imposing should not be confused with hyperaggressiveness, or with ancillary adversariality. It is a structural feature of the exchange we call argument. It is worth repeating that the compulsion of argument is not just a feature of persuasive argument involving disagreement. Rather, it is a feature of argument broadly understood - including that which aims to strengthen the beliefs someone already has (Perelman and Olbrechts-Tyteca, p. 49). To return to Govier's argument for minimal adversariality, I should stress that while Govier based the adversariality of belief in the difference of belief, in disagreement as it were, this version of her view discovers adversariality in the basic fact of manipulation of beliefs in argument. It is not because I have a different belief from you that we are adversaries, it is because of the lack of direct control I have over my own beliefs and you over yours.

Recent revelations about the 2016 United States presidential election poignantly illustrate the adversariality of agreement (Singer and Brooking 2018). Group polarization is a well-known phenomenon whereby people within like-minded groups tend to gravitate toward more extreme versions of the view they hold (Sunstein 2002). This feature of how humans process information can, of course, be exploited. While honey-tongued salespeople may convince you to change your belief that you do not need a car to a belief that you do, social media propagandists have specialized in making sure that your beliefs are maintained, or better, intensified. Social media algorithms, combined with the mechanisms of group polarization (Talisse 2019), provide advertisers and propagandists with privileged access to people's beliefs such that they know whom to target with reinforcing arguments. Unlike the case of the car salesperson, where one can protect oneself in advance by taking steps to avoid the arguments in the first place, social media algorithms exploit people's comfort with agreement. And they reap huge financial rewards because there is money to be made in validating people's beliefs (Singer and Brooking 2018, p. 132). With every "like" on social media platforms, users inform those who have access to that information what sorts of things they respond to. Data consultants, governments, and advertisers pur- 
chase that information and provide it to specialists. In the 2016 US Presidential election, Russian "troll farms" created millions of fake "bot" accounts aimed at giving people the impression that certain of their views, or views they were disposed to, were widely shared. What resulted, in essence, was that people became victims of their own beliefs. Agreement was turned against them.

Someone might object at this point that this is a misuse of the term "adversarial." The fact that all arguments involve attempting to compel others to believe something, including willing participants, clearly shows that argument is not adversarial in the negative sense often intended by critics of adversariality (Rooney, 2010; Hundleby, 2013). This is correct, if adversariality in this sense is understood not to be distinct from aggressiveness. For something to be adversarial, as I've argued above, is a structural matter. Aggressiveness, by contrast, may or may not apply to an adversarial encounter. I've argued that the involuntariness of believing is the reason that arguments have an adversarial structure. This means, minimally, that directed change of someone's beliefs has to happen independently of their will. This is not the same as saying that it happens without their consent. By way of analogy, if I play a game of chess, I may lose some of my pieces against my will, but I will have given my consent to play the game in the first place. I may, in fact I often do, enter an adversarial situation in order to have such involuntary encounters. In the case of believing, and so arguing, I need these in order to change and hopefully to improve the epistemic character of my beliefs.

There are other important consequences of the indirect voluntarism of believing that bear on the adversarial picture of argument. In the first place, what believing we can actually manage under the best of circumstances, we do with some effort and with uncertain results (Ahlstrom-Vij 2013). Belief revision is very difficult, and we are often unsuccessful (McFarland, Cheama and Buehler 2007; Godden 2012a). Second, engaging in argument can be a risky, and potentially costly, activity. Among the evident risks are the exposure of weaknesses in one's position, the exacerbation of disagreement, and emotional damage to participants (Paglieri and Castelfranchi 2010, p.74; see also Paglieri, 2009; Hample, Paglieri and $\mathrm{Na} 2012$ ). 
The costs of argument, however, do not end at the conclusion of the transaction. The desired results of arguing - beliefs - come with significant and unavoidable costs of their own. This is because beliefs are psychological states that are causally related to behavior. Consider the myriad costs that might accompany changing a view on, for instance, some public policy issue. These might include (1) a change in your attitude towards those who continue to hold that belief; (2) alteration of your social relations with those who hold those beliefs; (3) revision of other of your beliefs which would no longer be consistent; (4) embarrassment of having been wrong and having been corrected; (5) other social costs incurred by the change; (6) financial costs associated with the changes in belief; and (7) time and energy dedicated to new pursuits. Ideally, all arguments are good ones, with conclusions that are true and well-supported. But even these, perhaps especially these, will require costs such as these just described. These costs are not a side-effect or an irrelevant consideration, but rather the point of the whole enterprise. A conception of the adversarial features of argumentation as I have outlined here foregrounds the real costs of argument for potentially vulnerable human agents.

The costs associated with believing something coupled with the involuntariness of believing are just what makes argumentation adversarial. Offering arguments, after all, is the means of producing, maintaining, heightening, or extinguishing those beliefs in others. To be clear, argument is not adversarial because there is a competition for some kind of prize, or because it necessarily involves an opponent who disagrees, but rather because the interaction is characterized by involuntariness. This, as I have argued, is valid as much for our opponents as for our ideological fellow travellers. Indeed, there is even reason to believe that arguments pose an even greater danger to our friends than our enemies. They have given us the key. With this key we can compel in a way that far exceeds anything we can do with physical force.

\section{Conclusion}

As I conclude this paper, I would like to return to the general problem of adversarial argument, or what gets called the problem 
of adversarial argument, discussed at the beginning of the paper. If what I have argued here is correct, then there is in fact no escape from argument's essential adversariality. This view, I think, has significant implications for the various objections to argument's adversariality.

First off, a modified version of Trudy Govier's (1999) distinction between minimal and ancillary adversariality holds in this revised version of her view. Argument is essentially adversarial, and there is nothing we can do about that, but we can engage in it more or less aggressively. This is because the major difference, as I have argued, is that adversariality arises from interaction with the beliefs of another person rather than the fact of not sharing a belief with another person. You are an adversary with another person, in a minimal sense, because of how beliefs work and what kinds of practical, psychological, social, or economic consequences they have. This applies to the arguments founded in agreement, or those where arguers seek consensus, or collaborate, as much as the arguments where they differ. The fact that this works for agreement as much as disagreement is, on the one hand, a reason to view the minimal adversariality as less of a concern than it might otherwise have seemed. We do not worry, in other words, that our agreements are going to spin out of control into a full-blown war. On the other hand, it shows that our concerns about the adversariality of argument have indeed masked the fact that agreement, consensus, and collaboration can function as means of control, manipulation, or domination. Our focus on disagreement has blinded us to this possibility.

So, what of the other concerns about adversarial argument? If argument is fundamentally adversarial, then it will be like conflict or fighting in some minimal way. This means that, in some sense, the sports and war metaphors will not be entirely inappropriate. This is not, however, full-on license to apply war metaphors to argument. After all, many of these war (or sport) metaphors will nevertheless be mistaken because they project a mistaken conception of adversariality onto argument. Argument is not adversarial in the sense of interest. This means it cannot be won, and if there are prizes, they are extraneous to the core epistemic features of argument. What is ineliminably adversarial about argument is, 
again, the interaction. So, if anything, perhaps this revised conception of adversariality provides a clearer index as to how to apply adversarial metaphors in argument. It will make sense, for example, to speak of attacking a position, because indeed you are trying to rout someone from it. It even makes sense to speak of an arguer as heroic, beyond the literal danger of speaking, to the deeper psychological danger of putting their beliefs to the test.

\section{Acknowledgments}

Earlier versions of this paper were presented at Northeastern Illinois University, Vanderbilt University, the University of NevadaLas Vegas, and the International Society for the Study of Argumentation. I also received helpful feedback from Scott Aikin, Dan Cohen, David Godden, Fabio Paglieri, Jeanne Goodwin, Marcin Lewiński, Dan Milsky, Katharina Stevens, Catherine Hundleby, and two anonymous reviewers at Informal Logic.

\section{References}

Aikin, S. 2011. A Defense of war and sport metaphors in argument. Philosophy and Rhetoric 44: 250-272.

Ahlstrom-Vij, K. 2013. We cannot rely on ourselves for epistemic improvement. Philosophical Issues 23: 276-296.

Ayim, M. 1988. Violence and domination as metaphors in academic discourse. In Selected issues in logic and communication, ed. T. Govier, 184-195. Belmont, CA: Wadsworth.

Bäck, A. 2004. Thinking clearly about violence. Philosophical Studies 117: 219-230.

Bailin, S. and M. Battersby. 2017. DAMned if you do, DAMned if you don't: Cohen's "missed opportunities." In OSSA Conference Archive, 90. Retrieved from

https://scholar.uwindsor.ca/ossaarchive/OSSA11/papersandcomment aries $/ 90$

Brockriede, W. 1972. Arguers as lovers. Philosophy and Rhetoric 5: 111.

Brockriede, W. 1977. Characteristics of arguments and arguing. Journal of the American Forensic Association 13:129-132.

Cohen. D. 1995. Argument is war. . . and war is hell: Philosophy, education, and metaphors for argument. Informal Logic 17: 177-188. 
Cohen. D. 2013. For Argument's Sake. Retrieved from https://www.ted.com/talks/daniel h cohen for argument s sake?lan guage $=$ en

Cohen. D. 2014. Missed Opportunities in Argument Evaluation. In Reflections on Theoretical Issues in Argumentation Theory, eds. F.H. van Eemeren and B. Garssen. Argumentation Library 28.

DOI 10.1007/978-3-319-21103-9_9

Cohen, L.J. 1992. An essay on belief and acceptance. Oxford: Oxford University Press.

Eemeren, F.H. van and R. Grootendorst. 2004. A Systematic Theory of Argumentation. Cambridge: Cambridge University Press.

Foss, S. and C. Griffin. 1995. Beyond persuasion: A proposal for an invitational rhetoric. Communication Monographs 62: 2-18.

Fulkerson, R. 1995. Transcending our conception of argument in light of feminist critiques. Argumentation and Advocacy 32: 199-217.

Gearhart, S.M. 1979. The womanization of rhetoric. Women's Studies International Quarterly 2: 195-201.

Gilbert, M. A. 1996. How to win an argument. ( $\left.2^{\text {nd }} \mathrm{ed}\right)$. New York: Wiley.

Gilbert, M. A. 1997. Coalescent argumentation. Mahway, N.J.: Lawrence Erlbaum Associates.

Godden, D. 2010. The importance of belief in argumentation: Belief, commitment and the effective resolution of a difference. Synthese 172: 397-414.

Godden, D. 2012a. Rethinking the debriefing paradigm: The rationality of belief perseverance. Logos \& Episteme 3: 51-74.

Godden, D. 2012b. The role of mental states in argumentation: Two problems for rationality from the psychology of belief. In The goals of cognition: Essays in honor of Cristiano Castelfranchi F. Paglieri, eds, L. Tummolini, R. Falcone, and M. Miceli. 123-143. London: College Publications.

Godden D. 2015. Argumentation, rationality, and psychology of reasoning. Informal Logic 35: 135-166.

Goodwin, J. 2005. What does arguing look like? Informal Logic 25:7993.

Goodwin, J. 2007. Argument has no function. Informal Logic 27: 69-90.

Govier, T. 1999. The philosophy of argument. Newport News, VA: Vale.

Govier, T. 2010. A practical study of argument $\left(7^{\text {th }} \mathrm{ed}\right)$. Belmont, CA: Wadsworth.

Hamblin, C.L. 1970. Fallacies. London: Methuen. 
Hample, D., Paglieri, F. and L. Na. 2012. The costs and benefits of arguing: Predicting the decision whether to engage or not. In Topical themes in argumentation theory: Twenty exploratory studies, eds, F.H. van Eemeren and B. Garssen, 307-322. Dordrecht: Springer.

Horgan, J. 2017, January 13. What is philosophy's point? Part II: Maybe it's a martial art. Retrieved from https://blogs.scientificamerican.com/cross-check/what-isphilosophys-point-part-ii-maybe-its-a-martial-art/

Hundleby, C. 2013. Aggression, politeness, and abstract adversaries. Informal Logic 33: 238-262.

Hurley, P. 2008. A Concise Introduction to Logic $\left(10^{\text {th }} \mathrm{ed}\right)$. Belmont, CA: Thomson.

Infante, D.A. 1987. Aggressiveness. In Personality and Interpersonal Communication, eds. J.A. McCroskey and J.A. Daly, 157-192. Newbury Park, CA: Sage.

Jacobs, S. and S. Jackson 1980. Structure of conversational argument: Pragmatic bases for the enthymeme. The Quarterly Journal of Speech 66: 251-265.

Johnson, R. 2000. Manifest rationality. Mahwah, New Jersey: Lawrence Erlbaum Associates.

Krabbe, E.C.W. 2009. Cooperation and competition in argumentative exchanges. In Rhetoric and Argumentation in the Beginning of the XXIst Century, ed. H. Riberio. Coimbra: Coimbra University Press.

Lakoff, G. and M. Johnson. 1980. Metaphors we live by. Chicago: University of Chicago Press.

McFarland, C., Cheama, A. and R. Buehler. 2007. The perseverance effect in the debriefing paradigm: Replication and extension. Journal of Experimental Social Psychology 43: 233-240.

Moulton, J. 1983. A paradigm in philosophy: The adversary method. In Discovering reality, eds. S. Harding and M.B. Hintikka, 149-164. Boston: Reidel.

Nozick, R. 1981. Philosophical explanations. Cambridge, MA: The Belknap Press.

O'Keefe. D. 1977. Two Concepts of Argument. Journal of the American Forensic Association 13(3): 121-128.

O'Keefe, D. 1982. The concepts of argument and arguing. In Advances in argumentation theory and research, eds. J. R. Cox and C. A. Willard, 3-23. Carbondale: Southern Illinois University Press.

Paglieri, F. 2009. Ruinous arguments: escalation of disagreement and the dangers of arguing. In Argument Cultures: Proceedings of OSSA 08, eds. H. Hansen, C. Tindale, R. Johnson, and A. Blair. Windsor, ON: 
OSSA.

https://scholar.uwindsor.ca/ossaarchive/OSSA8/papersandcommentar ies/121/

Paglieri, F. and C. Castelfranchi. 2006. Belief and acceptance in argumentation: Towards an epistemological taxonomy of the uses of argument. In Proceedings of the Sixth International Conference on Argumentation, eds. F. H. van Eemeren, et al. Amsterdam: SicSat.

Paglieri, F. and C. Castelfranchi. 2010. Why argue? Towards a costbenefit analysis of argumentation. Argument and Computation 1: 7191.

Perelman, C. and L. Olbrechts-Tyteca. 1969. The new rhetoric, trans. J. Wilkinson and P. Weaver. Notre Dame, IN: University of Notre Dame Press.

Rooney, P. 2010. Philosophy, adversarial argumentation, and embattled reason. Informal Logic 30: 203-234.

Singer, P. W. and E. Brooking. 2018. Like war: The weaponization of social media. New York: Houghton Mifflin Harcourt.

Skultety, S. 2011. Categories of competition. Sport, Ethics, and Philosophy 5(4): 433-446.

Sunstein, C. 2002. The law of group polarization. Journal of Political Philosophy 10(2): 175-195.

Talisse, R. 2019. Overdoing democracy: Why we must put politics in its place. Oxford: Oxford University Press.

Walton, D. and E. Krabbe. 1995. Commitment in dialogue: Basic concepts of interpersonal reasoning. Albany: State University of New York Press.

Walton, D. 1998. The new dialectic: Conversational contexts of argument. Toronto: University of Toronto Press.

Willard, C.A. 1989. A theory of argumentation. Tuscaloosa, Alabama: University of Alabama Press. 